DOI: 10.17707/AgricultForest.65.3.06

\author{
Mykola NAZARENKO*, \\ Volodymyr BEIKO, Mykola BONDARENKO ${ }^{1}$
}

\title{
INDUCED MUTATIONS OF WINTER WHEAT CAUSED BY GAMMA- RAYS FIXED ON PLANT HEIGHT AND STEM STRUCTURE
}

\section{SUMMARY}

The objectives of our investigations are to describe the variation by mutations of stem architecture of the main groups of modern Ukrainian winter wheat varieties (8 varieties) due to their interactions with dose specific. Agronomic-value traits like as general short stem, dwarfs and semi-dwarfs have been investigated too. New perspective mutant lines have been obtained in terms of investigation. Main components for mutation breeding successful was genotype-mutagen interaction (due to factor analyses). By sensibility (in sense of number of mutations and type of mutations) genotypes can be subdivided on two groups. At the first group only varieties, which created with gamma-rays were observed. Gamma-rays were not useful for obtaining mutations by plant architecture for radiomutants varieties. Higher level of short-stem and semidwarfs mutation were inducted by 200 - 250 Gy doses, while for dwarfs in spite of dwarfs, which were observed more after $250 \mathrm{~Gy}$. Semi-dwarfs as mutations significance responded to gamma-rays action by changes with doses.

Key words: winter wheat, mutation breeding, plant height and structure, gamma-rays.

\section{INTRODUCTION}

Mutations have been used successful in several crops for breeding agronomical important traits. Induced mutations in wheat have been obtained for morphological and quantitative characters by treatment with different mutagens (Nazarenko et al, 2018). The main purpose of using mutagens has been to induce genetic variation, which is the first step in a breeding programmer. Grain yield, a complex polygenic trait is highly affected due to environmental stresses (Nazarenko and Kharitonov, 2016). Improvement of various complex traits can be possible through different breeding approaches. Induced mutations have significant impact along with conventional breeding approaches in cereals. Mutagenesis has become an established tool in plant breeding to supplement existing germplasm and to improve several specific morphological traits. More than 3500 varieties of plants obtained either as direct mutants or derived from their crosses and 2700 mutant varieties of different plants including cereal crops

\footnotetext{
${ }^{1}$ Mykola Nazarenko *(corresponding author: nik_nazarenko@ukr.net), Volodymyr Beiko, Mykola Bondarenko, Department of Plant Breeding and Seeds Production, Dnipro State Agrarian and Economic University, 49600, Dnipro, UKRAINE.

Notes: The authors declare that they have no conflicts of interest. Authorship Form signed online.
} 
have been released throughout the world through direct or indirect use of mutation breeding (IAEA, 2018).

Bread wheat (Triticum aestivum L.) with the annual production of about 757 million tons (in 2017) (USDA, 2018), is one of the world's most important cereal crops. Winter wheat is the world's leading cereal grain and the most important food crop, occupying first position in Ukraine. Ukrainian agriculture takes about $48 \%$ area under cereals and contributing $38 \%$ of the total food grain production in the country (Nazarenko, 2015).

The improvement of grain yield and yield components of wheat through application of mutagens leads towards improvement of new cultivars with improved traits. The use of induced mutations has thus become an important approach to plant breeding for the improvement of crop plants (Naveed et al, 2015).

The present studies were therefore undertaken to investigate the effects of gamma rays on various yield associated traits and to evaluate the value of induced mutations in wheat improvement.

Plant height is important agronomic traits related to plant architecture and grain yield in wheat. Tiller number and plant height are pointed out as two major agronomic traits in cereal crops affecting plant architecture and grain yield (Ellis et al, 2004). In investigation of chines researches of NAUH167, a new mutant of common wheat landrace induced by ethylmethyl sulfide treatment, exhibits higher tiller number and reduced plant height was attributed to the decrease in the number of cells and their length. Genetic analysis showed that the high-tillering number and dwarf phenotype were related and controlled by a partial recessive gene (Xu et al, 2017).

Dwarfing and semi-dwarfing mutations have mutual effects. As for example, dwarfing gene Rht-5 was associated with a plant height reduction, delaying heading date by 1 day, increasing the number of fertile tillers plant ${ }^{-1}$, while reducing the number of spikelets spike ${ }^{-1}$ and number of grains spike ${ }^{-1}$. The results of this study could be useful for proper use of Rht- 5 dwarfing gene in breeding programs to improve lodging tolerance, yield potential in wheat and increase efficiency of marker assisted selection for agronomic traits (Daoura et al, 2014).

Over the next decade, wheat grain production must increase to meet the demand of a fast growing human population. One strategy to meet this challenge is to raise wheat productivity by optimizing plant stature. As a sample of this investigation, the reduced height 8 (Rht8) semi-dwarfing gene is one of the few, together with the Green Revolution genes, to reduce stature of wheat (Triticum aestivum L.), and improve lodging resistance, without compromising grain yield. Rht8 is widely used in dry environments such as Mediterranean countries where it increases plant adaptability. With recent climate change, its use could become increasingly important even in more northern latitudes. Morphological analyses show that the semi-dwarf phenotype of Rht8 lines is due to shorter internodal 
segments along the wheat culm, achieved through reduced cell elongation and associated with stem mutations in our investigations (Gasperini et al, 2012).

The development of wheat mutants not only provided new genetic resources for wheat improvement, but also facilitated our understanding of the regulation of these traits at the molecular level. Identification of a dwarf mutant with a compact spike, NAUH164, produced from ethyl methyl sulfonate treatment of wheat variety Sumai 3, has reduced plant height and shortened spike length. Dwarfness and compact spike were controlled by a single dominant gene that was designated Rht23 (Chen et al, 2015).

Focused on only yield traits we have to understand that on high grain yield influence at complex many difference trait.

The objectives of our many-years investigations are to describe the genotypic variation of new mutant winter wheat lines by all spectra of the agronomic-value traits, investigation of consequences of main groups of breeding-useful mutagens treatment in interaction with modern winter wheat varieties. The most target objects are developing relations between genotype and nature of mutagen, mutagen dose, which determining the succeed of modern mutation breeding. Second our purpose to estimate new lines and their suitability as direct new varieties or components for future breeding crosses.

\section{MATERIAL AND METHODS}

Dried wheat grains (approx. 14\% moisture content, in brackets method of obtaining varieties or used mutagens) of 'Favoritka', 'Lasunya', 'Hurtovina' (irradiation of initial material by gamma rays), line 418, 'Kolos Mironovschiny' (field hybridization), 'Sonechko' (chemical mutagenesis, nitrosodimethilurea (NDMU) 0.005\%) and 'Kalinova' (chemical mutagenesis,1.4bisdiazoatsetilbutan DAB 0.1\%), 'Voloshkova' (termomutagenesis - low plus temperature at plant development stage of vernalizaion has been used as mutagen factor) of winter wheat (Triticum aestivum L.) were subjected to 100, 150, 200, 250 Gy gamma irradiation (rapid dose, $\mathrm{Co}^{60}, 0.048 \mathrm{~Gy} / \mathrm{s}$ ). Each treatment was comprised of 1,000 wheat seeds. Non-treated varieties were used as a control for mutation identified purpose (Nazarenko, 2015).

Treated seeds were grown in rows with inter and intra-row spacing of 50 and $30 \mathrm{~cm}$, respectively, to raise the M1 population. The untreated seeds of mother varieties (parental line/variety) were also planted after every ten rows as control for comparison with the M1 population. M1 plant rows were grown in three replications with check-rows of untreated varieties in every ten-row interval (Nazarenko, 2017).

In $\mathrm{M}_{2}-\mathrm{M}_{3}$ generations productive and other value families have been selected via visual estimation. The sowing was done by hand, at the end of September, at a depth of $4-5 \mathrm{~cm}$ and with a rate of 100 viable seeds to a row (length $1.5 \mathrm{~m}$ ), interrow was $15 \mathrm{~cm}$, between samples $30 \mathrm{~cm}, 1-2$ rows for sample with control-rows of untreated varieties in every twenty-sample interval. 
Estimation of total yield per plot and its components was conducted from 2014 to 2018 years $\left(M_{4}-M_{8}\right.$ generations). The controls were national standard by productivity 'Podolyanka' and initial variety. The working-methods in the breeding trials are satisfied to state variety exam requests. The trial was set up as a randomized block design method with three replications and with a plot size of from 5 to $20 \mathrm{~m}^{2}$ in $2-3$ replications. (Shu et al., 2013).

Experiments were conducted on the experiment field of Dnipropetrovsk State Agrarian-Economic University (village Aleksandryvka, Dnipropetrovsk district, Dnipropetrovsk region, Ukraine). Normal cultural practices including fertilization were done whenever it is necessary. Evolution was conducted during 2011 - 2018 years.

Mathematical processing of the results was performed by the method of analysis of variance, the variability of the mean difference was evaluated by Student's t-test, the grouping mutants cases was performed by cluster analysis, factor analyses was conducted by module ANOVA. In all cases standard tools of the program Statistica 8.0 were used.

\section{RESULTS AND DISCUSSION}

Total size of population 17600 families at second-third generation (include controls) and represented by variants of mutagen treatment at table 1 . Investigators ran on with trivial problem for high doses limited number of material for next stapes of breeding process (Nazarenko, 2016a; Nazarenko, 2017b).

From $\mathrm{M}_{2}-\mathrm{M}_{3}$ generations 1,482 potential productivity winter wheat mutation lines and 5,862 lines with mutation changes were determined overall (table 1).

The main purpose of our investigation was to determine rate and spectra of winter wheat mutations by plant height and steam structure(high steam (more than $1 \mathrm{~m})$, short steam $(0.6-0.8 \mathrm{~m})$, semi-dwarf $(0.2-0.4 \mathrm{~m})$ and dwarf $(0.2-$ $0.4 \mathrm{~m}$ ), thick and thin stem) after gamma-rays action and develop relations between number and type of mutations and gamma-rays doses, genotypes of mutation object.

General spectra of mutations have been grouped on six groups (38 traits) according to general practice. In this investigation part of first group (mutations of stem structure) has been analyzed. Visible mutation changes and their heredity in the course of several generations have been summarized.

From previous investigations fact of decreasing general mutation rates and number of mutation traits (level of changeability) for radiomutants after gammarays action has been developed. Regarding dates of table $2-4$ any statistically reliable difference between rates in this group between three types of genotypes hasn't been observed.

General mutation rate to all types mutation has been increased until level of $200 \mathrm{~Gy}$ dose. After reached this dose, number of mutation up to $250 \mathrm{~Gy}$ was significantly lower. Just the same to the level of changeability (parameter to 
overall score rate of mutations and number of mutations types). High level of changeability was corresponded to dose 150 - $200 \mathrm{~Gy}$.

Table 1. Number of mutant families at second - third generations

\begin{tabular}{|c|c|c|c|c|c|c|c|c|}
\hline Trial & 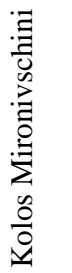 & 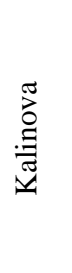 & $\begin{array}{l}\frac{0}{0} \\
\frac{0}{\overline{0}} \\
\frac{0}{0} \\
\frac{0}{0}\end{array}$ & 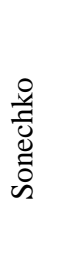 & 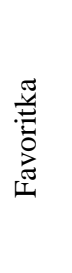 & $\begin{array}{l}\text { 茵 } \\
\text { 总 } \\
\text { 坣 }\end{array}$ & 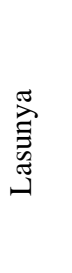 & 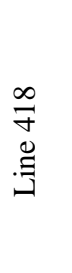 \\
\hline Control & 500 & 500 & 500 & 500 & 500 & 500 & 500 & 500 \\
\hline Gamma-rays, 100 Gy & 500 & 500 & 500 & 500 & 500 & 500 & 500 & 500 \\
\hline Gamma-rays, 150 Gy & 500 & 500 & 500 & 400 & 500 & 500 & 500 & 500 \\
\hline Gamma-rays, 200 Gy & 500 & 350 & 500 & 250 & 450 & 500 & 450 & 400 \\
\hline Gamma-rays, $250 \mathrm{~Gy}$ & 300 & 350 & 500 & 100 & 400 & 400 & 350 & 400 \\
\hline
\end{tabular}

Table 2. Spectrum of mutations under gamma-rays action (radiomutants)

\begin{tabular}{|c|c|c|c|c|c|c|c|c|c|c|c|}
\hline \multirow{2}{*}{$\mathrm{N}$} & \multirow{2}{*}{ Trait } & \multicolumn{2}{|c|}{ Check } & \multicolumn{2}{|c|}{100 Gy } & \multicolumn{2}{|c|}{150 Gy } & \multicolumn{2}{|c|}{200 Gy } & \multicolumn{2}{|c|}{250 Gy } \\
\hline & & lines & $\%$ & lines & $\%$ & lines & $\%$ & lines & $\%$ & lines & $\%$ \\
\hline \multicolumn{12}{|c|}{ variety Favoritka } \\
\hline 1 & high stem & 0 & 0.0 & 2 & 0.4 & 3 & 0.6 & 4 & 0.9 & 4 & 1.0 \\
\hline 2 & short stem & 1 & 0.2 & 2 & 0.4 & 2 & 0.4 & 2 & 0.4 & 3 & 0.75 \\
\hline 3 & semi-dwarf & 0 & 0.0 & 0 & 0.0 & 0 & 0.0 & 2 & 0.4 & 1 & 0.25 \\
\hline 4 & dwarf & 0 & 0.0 & 0 & 0.0 & 0 & 0.0 & 1 & 0.2 & 1 & 0.25 \\
\hline \multicolumn{12}{|c|}{ variety Hurtovina } \\
\hline 1 & high stem & 0 & 0.0 & 5 & 1.0 & 5 & 1.0 & 4 & 0.8 & 3 & 0.8 \\
\hline 2 & short stem & 0 & 0.0 & 3 & 0.6 & 3 & 0.6 & 4 & 0.8 & 2 & 0.5 \\
\hline 3 & semi-dwarf & 0 & 0.0 & 0 & 0.0 & 0 & 0.0 & 2 & 0.4 & 1 & 0.3 \\
\hline 4 & dwarf & 0 & 0.0 & 0 & 0.0 & 0 & 0.0 & 2 & 0.4 & 1 & 0.3 \\
\hline \multicolumn{12}{|c|}{ variety Lasunya } \\
\hline 1 & high stem & 2 & 0.4 & 1 & 0.2 & 2 & 0.4 & 3 & 0.7 & 1 & 0.3 \\
\hline 2 & short stem & 2 & 0.4 & 4 & 0.8 & 2 & 0.4 & 3 & 0.7 & 3 & 0.9 \\
\hline 3 & semi-dwarf & 0 & 0.0 & 0 & 0.0 & 1 & 0.2 & 2 & 0.4 & 2 & 0.6 \\
\hline 4 & dwarf & 0 & 0.0 & 0 & 0.0 & 0 & 0.0 & 1 & 0.2 & 2 & 0.6 \\
\hline
\end{tabular}

The same tendentious was expected from this group of mutations, but dates were not so clearly and sometimes a little contradictory. 
Table 3. Spectrum of mutations under gamma-rays action (chemomutants)

\begin{tabular}{|c|c|c|c|c|c|c|c|c|c|c|c|}
\hline \multirow{2}{*}{$\mathrm{N}$} & \multirow{2}{*}{ Trait } & \multicolumn{2}{|c|}{ Check } & \multicolumn{2}{|c|}{100 Gy } & \multicolumn{2}{|c|}{150 Gy } & \multicolumn{2}{|c|}{200 Gy } & \multicolumn{2}{|c|}{250 Gy } \\
\hline & & lines & $\%$ & lines & $\%$ & lines & $\%$ & lines & $\%$ & lines & $\%$ \\
\hline \multicolumn{12}{|c|}{ variety Kalinova } \\
\hline 1 & high stem & 4 & 0.8 & 4 & 0.8 & 6 & 1.2 & 6 & 1.2 & 0 & 0.0 \\
\hline 2 & short stem & 1 & 0.2 & 5 & 1.0 & 13 & 2.6 & 13 & 2.6 & 4 & 0.8 \\
\hline 3 & semi-dwarf & 0 & 0.0 & 0 & 0.0 & 1 & 0.2 & 3 & 0.6 & 4 & 0.8 \\
\hline 4 & dwarf & 0 & 0.0 & 0 & 0.0 & 0 & 0.0 & 1 & 0.2 & 5 & 1.0 \\
\hline \multicolumn{12}{|c|}{ variety Sonechko } \\
\hline 1 & thick stem & 0 & 0.0 & 1 & 0.2 & 0 & 0.0 & 0 & 0.0 & 0 & 0.0 \\
\hline 2 & thin stem & 0 & 0.0 & 1 & 0.2 & 0 & 0.0 & 0 & 0.0 & 0 & 0.0 \\
\hline 3 & high stem & 0 & 0.0 & 7 & 1.4 & 8 & 2.0 & 17 & 6.8 & 0 & 0.0 \\
\hline 4 & short stem & 0 & 0.0 & 4 & 0.8 & 6 & 1.5 & 4 & 1.6 & 1 & 1.0 \\
\hline 5 & semi-dwarf & 0 & 0.0 & 0 & 0.0 & 4 & 1.0 & 2 & 0.8 & 1 & 1.0 \\
\hline 6 & dwarf & 0 & 0.0 & 0 & 0.0 & 1 & 0.25 & 1 & 0.4 & 1 & 1.0 \\
\hline
\end{tabular}

For first group similar number of mutations was characterized to all dose, but partly lower for $250 \mathrm{~Gy}$. Rates of mutations are not high. Only for dwarf mutations are caused by $200-250$ Gy doses only. For variety Lasunya more quantity of short-stem mutation was characterized.

Seldom mutations of stem thickness cannot be observed at all cases, and were appeared only in other groups and only for genotypes Sonechko, Kolos Mironivschini, Voloshkova. Rate of this type of changes was not high and only after 150 - 250 (more prevalent 200 - 250 Gy) action.

For second group (table 3 ) higher rate of mutations was developed. The same direction was saved, but doses 150 - 200 Gy significance preferable to this type of mutations (especially for short stem and semi-dwarf mutations, for dwarfs 250 Gy more suitable).

Regarding table 4 the same situation was observed with peak at doses 150 - 200 Gy and lower number of mutations at 250 Gy. Generally, mutation rate was varied from 0,2 to $1,6 \%$ (line $418,100 \mathrm{~Gy}$ ) for high steam, from 0,2 to 2,8 \% (line 418, $200 \mathrm{~Gy}$ ) for short steam, from 0,2to 1,0 \% (variety Sonechko, line 418, 150 - $200 \mathrm{~Gy}$ ) for semi-dwarfs and from absence to the 100 -150 Gy doses for some genotypes to $0,6 \%$ (line 418, $200 \mathrm{~Gy}$ ) for dwarfs forms (table 2 - 4).

Mutations types thick and thin stem are characterized only for three varieties (at $100-200 \mathrm{~Gy}$ ) and for no one radiomutants. Rates by these traits are very lower at all three cases. It's in accordance to generally direction in decreasing type of mutations and variability level for these types of genotypes.

We can subdivided initial material by the method of breeding as radiomutants (Favoritka, Hurtovina, Lasunya), chemomutants (Kalinova and Sonechko), thermomutants (low plus temperature at plant development stage of 
vernalizaion has been used as mutagen factor) (Voloshkova) and forms, obtained after hybridization (Kolos Mironivschini, line 418).

Table 4. Spectrum of mutations under gamma-rays action (hybrid varieties)

\begin{tabular}{|c|c|c|c|c|c|c|c|c|c|c|c|}
\hline \multirow{2}{*}{$\mathrm{N}$} & \multirow{2}{*}{ Trait } & \multicolumn{2}{|c|}{ Check } & \multicolumn{2}{|c|}{100 Gy } & \multicolumn{2}{|c|}{150 Gy } & \multicolumn{2}{|c|}{200 Gy } & \multicolumn{2}{|c|}{250 Gy } \\
\hline & & lines & $\%$ & lines & $\%$ & lines & $\%$ & lines & $\%$ & lines & $\%$ \\
\hline \multicolumn{12}{|c|}{ variety Kolos Mironivschini } \\
\hline 1 & thick stem & 0 & 0.0 & 0 & 0.0 & 0 & 0.0 & 2 & 0.4 & 0 & 0 \\
\hline 2 & thin stem & 0 & 0.0 & 0 & 0.0 & 1 & 0.2 & 0 & 0.0 & 0 & 0 \\
\hline 3 & high stem & 1 & 0.2 & 6 & 1.2 & 11 & 2.2 & 8 & 1.6 & 3 & 1.0 \\
\hline 4 & short stem & 1 & 0,2 & 9 & 1.8 & 4 & 0.8 & 4 & 0.8 & 9 & 3.0 \\
\hline 5 & semi-dwarf & 0 & 0.0 & 0 & 0.0 & 2 & 0.4 & 3 & 0.6 & 3 & 1.0 \\
\hline 6 & dwarf & 0 & 0.0 & 0 & 0.0 & 0 & 0.0 & 3 & 0.6 & 4 & 1.3 \\
\hline \multicolumn{12}{|c|}{ variety Voloshkova } \\
\hline 1 & thick stem & 0 & 0.0 & 0 & 0.0 & 0 & 0.0 & 1 & 0.2 & 0 & 0.0 \\
\hline 3 & thin stem & 0 & 0.0 & 0 & 0.0 & 0 & 0.0 & 1 & 0.2 & 1 & 0.2 \\
\hline 4 & high stem & 3 & 0.6 & 1 & 0.2 & 4 & 0.8 & 1 & 0.2 & 0 & 0.0 \\
\hline 5 & short stem & 4 & 0.8 & 4 & 0.8 & 3 & 0.6 & 8 & 1.6 & 4 & 0.8 \\
\hline 6 & semi-dwarf & 0 & 0.0 & 1 & 0.2 & 1 & 0.2 & 1 & 0.2 & 3 & 0.6 \\
\hline \multicolumn{12}{|c|}{ line 418} \\
\hline 1 & high stem & 1 & 0.2 & 8 & 1.6 & 6 & 1.2 & 4 & 1.0 & 1 & 0.3 \\
\hline 2 & short stem & 0 & 0.0 & 4 & 0.8 & 5 & 1.0 & 11 & 2.8 & 4 & 1.0 \\
\hline 3 & semi-dwarf & 0 & 0.0 & 1 & 0.2 & 2 & 0.4 & 4 & 1.0 & 1 & 0.3 \\
\hline 4 & dwarf & 0 & 0.0 & 0 & 0.0 & 1 & 0.2 & 3 & 0.8 & 1 & 0.3 \\
\hline
\end{tabular}

Thus, mutants with thick stem - rate of occurrence from 0 to $0,4 \%$, probability of occurrence - low (only for 3 varieties), patterns of occurrence for doses and genotypes were not found; thin stems from 0 to $0.2 \%$ are unlikely to occur predominantly in the same variants (and exclusively in the same varieties) as the previous mutation; high-stem mutations - the frequency of occurrence in the average of $0.9 \%$, high-frequency mutation, occurring in any variants; lowstem - high probability of occurrence, but more rarely than high-stem, an average of $0.7 \%$, the frequency in some variants of up to $3 \%$; half-dwarfs is also highly probable, but less than the previous one, up to $1 \%$, on average - $0,3 \%$, typical for up to 150 - $200 \mathrm{~Gy}$. The dwarf is also a highly probable mutation, but less than the previous one, to $1.3 \%$, an average of $0.2 \%$, preferably at the action of 200 250 Gy.

According to our investigations more effectiveness at mutation induction were for high steam form doses $100-150 \mathrm{~Gy}$, for short steam mutants $100-150$ Gy, for both semi-dwarf and dwarf forms 150 - 250 Gy with peak for most part 
of genotypes at 200 Gy dose. Part of genotypes (preferable radiomutants) hasn't been shown these kinds of changes at 100 - 150 Gy doses at all.

Regarding analyze of these groups it has been developed that rate of these types of mutations was significantly lower for first group, than for others. According to ANOVA analyses number of mutations was depended on dose at all cases, relation with genotype and mutation rate has been identified with significance reliability for only one case short stem mutations (F 2,49, $F_{\text {critical }}$ $2,36)$. In spite of this fact, genotype and mutagen interaction are statistically reliable for all cases and traits.

Due to the discriminant analyses only fact of semi-dwarfs mutants appearance can be used as indicator of gamma-ray action for initial material classification (Wilks Lambda 0.305508, F-remove 2.786654)

\section{CONCLUSIONS}

In the present study, a mutagenized wheat population is developed using gamma-rays. Plant height mutations as well as mutants by stem are identified. These stable mutants are developed as lines at the next generations. The generated information would be useful in developing new winter wheat cultivars from mutants lines either direct or through hybridization program.

Due to results of our investigations gamma-rays irradiated as a method for creation new variation material on plant height and stem structure has been shown as very successful. Large number of material has been obtained both as for perspective new varieties and as the sources for future winter wheat breeding program for changing plant architecture. Only one trait appeared significant influence of genotype as a key component for mutation breeding success but at all times genotype-mutagen interaction regarding results of ANOVA analyze was significance in its influence on mutation rates. The same situation was for factor dose of gamma-rays, but the first-place component was interaction of gammarays and genotype.

Gamma-rays were not effective to radiomutants for mutations by stem high. Doses of 200 - 250 Gy were more preferable to short-stem and semi-dwarfs mutation obtaining, in spite of dwarfs, which were observed more after $250 \mathrm{~Gy}$.

\section{REFERENCES}

Daoura, B., Chen, L., Du, Y., Hu, Y., 2014 Genetic effects of dwarfing gene Rht-5 on agronomic traits in common wheat (Triticum aestivum L.) and QTL analysis on its linked traits. Field Crop Research. 156 (1), 22-29.

Chen, S., Gao, R., Wang, H., Wen, M., Xiao, J, Bian, N., Zhang, R., Hu, W., Cheng, S., Bie, T., Wang, X., 2015. Characterization of a novel reduced height gene (Rht23) regulating panicle morphology and plant architecture in bread wheat. Euphytica. 203, 583-594.

Ellis, M., Rebetzke, G., Chandler, P., Bonnett, D., Spielmeyer, W., Richards, R., 2004. The effect of different height reducing genes on the early growth of wheat. Functional Plant Biology. 31, 583-589. 
Gasperini, D., Greenland, A., Hedden, P., Dreos, R., Harwood, W., Griffiths, S., 2012. Genetic and physiological analysis of Rht8 in bread wheat: an alternative source of semi-dwarfism with a reduced sensitivity to brassinosteroids. Journal of Experimental Botany. 63, 4419-4436.

International Atomic Energy Agency (2018) Mutant varieties database. [Online] Vienna: IAEA. Available at: https://mvd.iaea.org [Accessed 6 February 2018].

Naveed, A., Nazir, A., Abdul, H., Raza, S., Muhammad, A., 2015. Mutation breeding: a tool to improve wheat yield and yield components. Life Science. 9 (1), 3274-3279

Nazarenko, M., 2015. Negativnyie posledstviya mutagennogo vozdeystviya [Peculiarities of negative consequences of mutagen action], Ecological Genetics, 4, 25-26. (in Russian).

Nazarenko, M., Kharytonov, M., 2016. Characterization of wheat mutagen depression after gamma-rays irradiated. In: Agriculture and Forestry, 62, 4, 267-276.

Nazarenko, M., 2017. Specific Features in the Negative Consequences of a Mutagenic Action. In: Russian Journal of Genetics: Applied Research, 7, 2, 195-196.

Nazarenko, M., Lykholat, Y., Grigoryuk, I., Khromykh, N., 2018 Optimal doses and concentrations of mutagens for winter wheat breeding purposes. Part I. Grain productivity. Journal of Central European Agriculture. 19(1). 194-205.

Shu, Q.Y., Forster, B.P., Nakagava, H., 2013. Plant mutation breeding and biotechnology. Vienna: CABI publishing.

World Agricultural Supply and Demand Estimates. USDA, Washington, 2018. Retrieved from https://www.usda.gov/oce/commodity/wasde/latest.pdf.

Xu, T., Bian, N., Wen, M., Xiao, J., Yuan, C., Cao, A., Zhang, S., Wang, X., Wang, H., 2017. Characterization of a common wheat (Triticum aestivum L.) high-tillering dwarf mutant. Theoretical Applied Genetic. 130 (3), 483-494. 